\title{
Paired-Pulse Inhibition in the Auditory Cortex in Parkinson's Disease and Its Dependence on Clinical Characteristics of the Patients
}

\author{
Elena Lukhanina, ${ }^{1}$ Natalia Berezetskaya, ${ }^{2}$ and Irina Karaban ${ }^{2}$ \\ ${ }^{1}$ Department of Brain Physiology, Bogomoletz Institute of Physiology, 01024 Kiev, Ukraine \\ ${ }^{2}$ Parkinson's Disease Treatment Centre, Institute of Gerontology, 04114 Kiev, Ukraine
}

Correspondence should be addressed to Elena Lukhanina, luh@biph.kiev.ua

Received 24 June 2010; Revised 16 September 2010; Accepted 29 September 2010

Academic Editor: Irena Rektorova

Copyright (C) 2011 Elena Lukhanina et al. This is an open access article distributed under the Creative Commons Attribution License, which permits unrestricted use, distribution, and reproduction in any medium, provided the original work is properly cited.

\begin{abstract}
We aimed to determine the value of the paired-pulse inhibition (PPI) in the auditory cortex in patients with Parkinson's disease $(\mathrm{PD})$ and analyze its dependence on clinical characteristics of the patients. The central $(\mathrm{Cz})$ auditory evoked potentials were recorded in 58 patients with $\mathrm{PD}$ and 22 age-matched healthy subjects. PPI of the N1/P2 component was significantly $(P<.001)$ reduced for interstimulus intervals 500, 700, and $900 \mathrm{~ms}$ in patients with PD compared to control subjects. The value of PPI correlated negatively with the age of the PD patients $(P<.05)$, age of disease onset $(P<.05)$, body bradykinesia score $(P<.01)$, and positively with the Mini Mental State Examination (MMSE) cognitive score $(P<.01)$. Negative correlation between value of PPI and the age of the healthy subjects $(P<.05)$ was also observed. Thus, results show that cortical inhibitory processes are deficient in PD patients and that the brain's ability to carry out the postexcitatory inhibition is age-dependent.
\end{abstract}

\section{Introduction}

Parkinson's disease (PD) is a neurodegenerative disorder primarily related to pathology in the substantia nigra pars compacta dopaminergic neurons that results in the development of the brain dopamine deficit. The mechanisms and pathophysiology of this disease are not completely understood [1]. Although the cardinal features of the disease are movement disorders (rigidity, tremor, bradykinesia), the manifestations of $\mathrm{PD}$ also comprise a variety of diverse abnormalities including disturbance of sensory gating and cognitive decline [2-4].

It has been previously reported that disorders in $\mathrm{PD}$ largely occur due to the imbalance of inhibitory and excitatory processes in cortical and subcortical neuronal circuits [5-10]. A paired-pulse paradigm is usually used to study postexcitatory inhibition effect related to sensory gating mechanisms and synaptic processes in neurotransmitters release $[11,12]$. There are two mechanisms that might explain paired-pulse inhibition (PPI) phenomena. The first mechanism is the decrease in release probability of excitatory neurotransmitters from terminals of afferent axons [13-15]. This effect is likely the result of an inhibition of calcium influx through presynaptic receptors which play a causal role in the release of glutamate from synaptic vesicles on afferent stimulation [16]. Another possible mechanism of the decrement of the second response on paired stimulation is connected with synaptically released GABA from terminals of inhibitory interneurons [17-19]. As the paired-pulse facilitation, PPI is considered to be a form of a short-term synaptic plasticity $[20,21]$.

Several studies demonstrated a decreased postexcitatory inhibition of the midlatency (P 49) auditory evoked responses and median nerve somatosensory evoked potentials (P13-N18, P24-N31, P44-N75) on paired stimulation in patients with $\mathrm{PD}$ compared to healthy age-matched people $[22,23]$. In the work of Perriol et al., the authors revealed a pronounced reduction of the prepulse inhibition of the N1/P2 component of auditory evoked potentials in PD and dementia with Lewy bodies [24]. In our previous study, 
we showed reduction of the postexcitatory inhibition of the N1/P2 complex in the auditory cortex in patients with PD and positive effect of Levodopa administration on its value [25].

The aim of this study was to analyze the dependence of the PPI value of the N1/P2 component of auditory cortical evoked potentials on the clinical parameters of the PD patients: age, sex, disease duration, age at disease onset, Hoehn and Yahr stage, duration of the Levodopa intake, Levodopa dosage, and indices of motor and cognitive functions determined by using Unified Parkinson's Disease Rating Scale (UPDRS) and Mini Mental State Examination (MMSE).

\section{Subjects and Methods}

2.1. Subjects and Study Conditions. Studies were performed in two groups. The first group included $58 \mathrm{PD}$ patients, with the severity of the disease corresponding to 1.5-3.0 of Hoehn and Yahr [26] scale (28 men and 30 women, mean \pm SE age $61.5 \pm 1.1$, range $45-74$ years). The second group was control and had 22 age-matched healthy subjects (10 men and 12 women, mean \pm SE age $61.4 \pm 1.2$, range $48-73$ years).

The study was approved in advance by the Ethical Committee of the Institute of Gerontology and was in accordance with the Helsinki declaration. The patients regularly underwent treatment at the Parkinson's Disease Centre of the Institute of Gerontology and gave written informed consent to participate in this study. The diagnosis of Parkinson's disease was determined according to the UK Bank Criteria [27]. The patients had from 2 to 22 year individual histories of idiopathic PD and were taking antiparkinsonian therapy at individual doses of 187.5-700 mg of Levodopa/Carbidopa daily. Besides Levodopa/Carbidopa, the patients were using other antiparkinsonian medication: Selegiline, Pramipexol, and Amantadine. The neurological status of PD patients was evaluated with UPDRS $[28,29]$ in the ON state one hour after Levodopa/Carbidopa intake. MMSE was used to study general cognitive status of the $\mathrm{PD}$ patients. The 53 (91\%) individuals with PD did not show substantial dysfunctions in memory, attention, or orientation and the averaged value of the MMSE scores for whole group was relatively high $(27.9 \pm 0.3)$. Only $5(9 \%)$ subjects had scores of 24 (i.e., a boundary index testifying to the doubtful signs of cognitive dysfunction). Table 1 represents the details of the PD patients' evaluation.

Auditory evoked potentials were recorded in the PD patients in their "OFF" state in the morning, after they were free from Levodopa treatment and other antiparkinsonian medications for at least 12 hours.

2.2. Recordings. The subjects were sitting comfortably in a semireclined armchair in a quiet room with closed eyes. Auditory evoked potentials were recorded at the vertex $(\mathrm{Cz})$ referenced to a linked-ear electrode. The ground electrode was placed at the left wrist. The impedance of the electrodes was less than $10 \mathrm{k} \Omega$. The electrode signal was amplified using a band pass filter $(0.53-30 \mathrm{~Hz})$, digitized with $200 \mathrm{~Hz}$ sampling rate, and stored for further analysis.
TABle 1: Backgrounds of patients with Parkinson's disease.

\begin{tabular}{|c|c|}
\hline Total No of patients & 58 \\
\hline Men & 28 \\
\hline Women & 30 \\
\hline Age, years $($ Mean \pm SE) & $61.5 \pm 1.1(45-74)$ \\
\hline $\begin{array}{l}\text { Duration of illness, years } \\
(\text { Mean } \pm \text { SE) }\end{array}$ & $7.6 \pm 0.7(2-22)$ \\
\hline \multicolumn{2}{|l|}{$\begin{array}{l}\text { Hoehn and Yahr stage } \\
\text { (No of cases) }\end{array}$} \\
\hline Stage 1.5 & 4 \\
\hline Stage 2.0 & 25 \\
\hline Stage 2.5 & 14 \\
\hline Stage 3.0 & 15 \\
\hline UPDRS scores $($ Mean \pm SE) & $58.6 \pm 2.2(29-94)$ \\
\hline MMSE scores (Mean \pm SE) & $27.9 \pm 0.3(24-30)$ \\
\hline $\begin{array}{l}\text { Levodopa dosage }{ }^{*}, \mathrm{mg} / \text { day } \\
(\text { Mean } \pm \mathrm{SE}) ; 46 \text { cases }\end{array}$ & $359.2 \pm 23.3(187.5-700)$ \\
\hline
\end{tabular}

The pattern for double stimulation consisted of paired auditory clicks with 500, 700, and 900 ms interstimulus intervals (ISIs). The identical parameters (duration of $0.15 \mathrm{~ms}$ and intensity of $80 \mathrm{~dB}$ HL-hearing level) were used for the preceding conditioning click and following test click. Pairs of clicks were delivered once every $7 \mathrm{~s}$ for each ISI. Previous studies have shown that stimulation at faster frequencies can lead to a decrement in the cortical evoked potentials [30, 31]. A 2000-3000 ms electroencephalography (EEG) epoch was recorded for each trial, including a $300 \mathrm{~ms}$ prestimulus baseline. The recording time depended on ISIs. The epochs contaminated with blinks or other artifacts were excluded from the data and twenty acceptable artifact-free trials were averaged for each ISI and used for further analysis.

2.3. Data Analysis. In EEG recordings to paired stimulation, amplitudes of N1-P2 complex (peak to peak) in the first (A1) and the second (A2) responses were measured. The amplitudes of the components $\mathrm{N} 1$ and $\mathrm{P} 2$ were estimated in the $60-150 \mathrm{~ms}$ and $120-220 \mathrm{~ms}$ ranges of time, respectively. The percent PPI of the N1-P2 complex was calculated using the following formula: (A1 - A2)/A1*100.

The results were analyzed statistically. Comparisons between PD patients and control groups were made using the nonparametric two-tailed Mann-Whitney criterion and ANOVA statistics. The nonparametric Spearman test was used to evaluate possible correlation between the value of PPI and characteristics of the investigated cohorts.

\section{Results}

3.1. Exploration of the Postexcitatory Inhibition upon Paired Stimulation. Results showed a significant difference in PPI of the N1/P2 component of auditory cortical evoked potentials in two investigated groups. In PD patients, the postexcitatory 


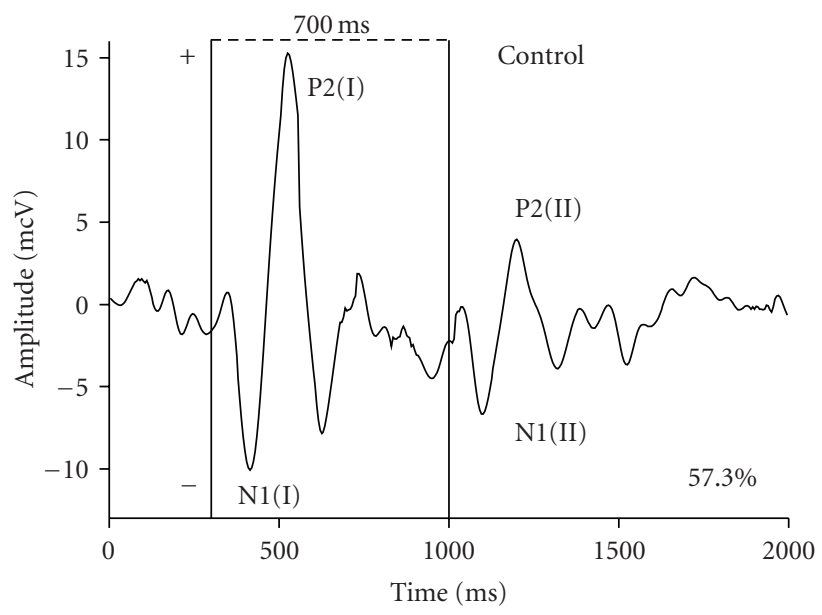

(a)

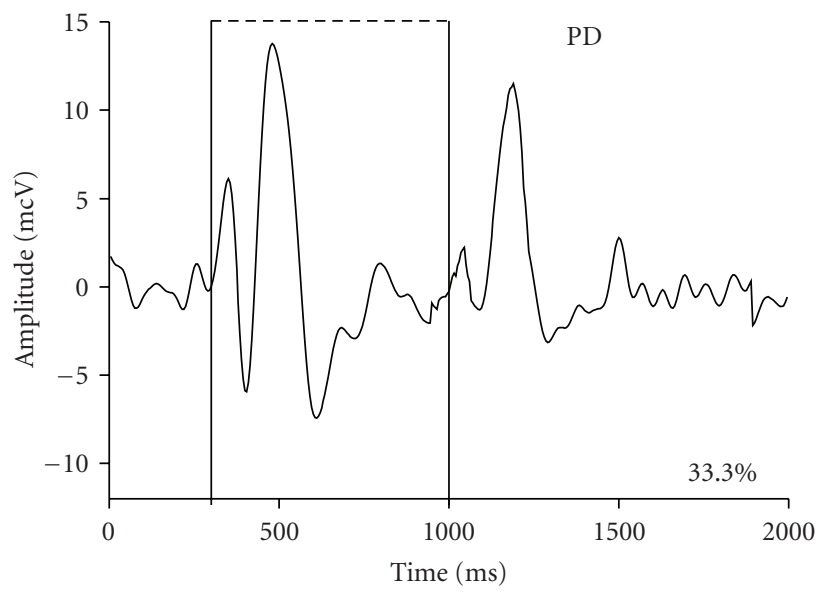

(c)

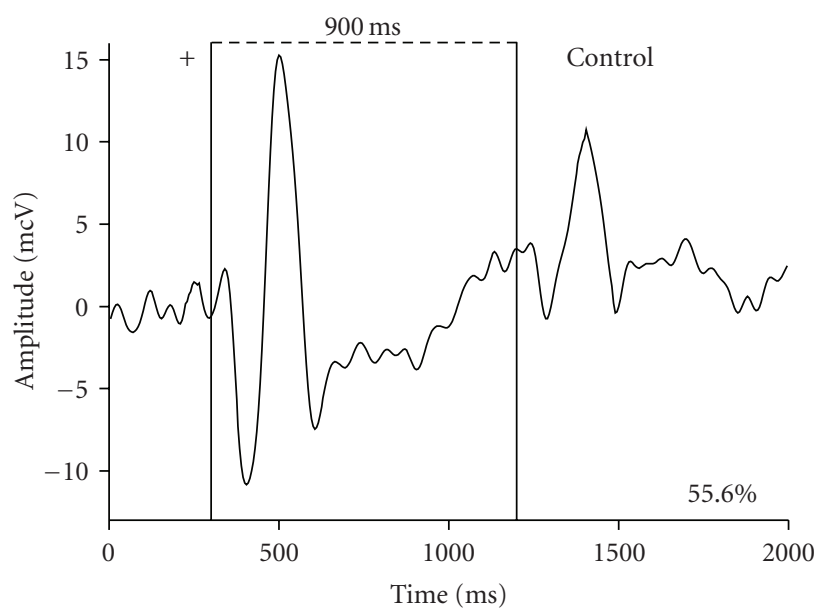

(b)

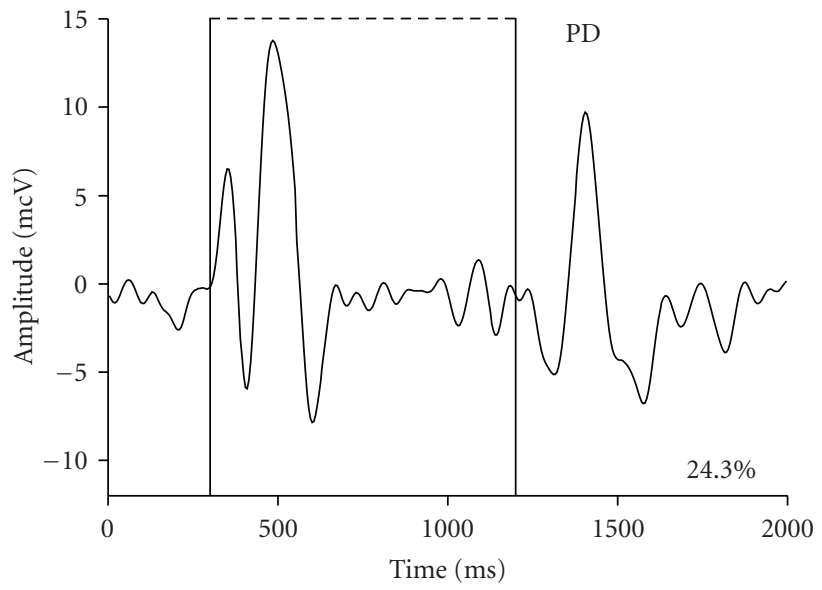

(d)

FIGURE 1: Cortical auditory evoked potentials at paired-pulse stimulation with interstimulus intervals 700 and $900 \mathrm{~ms}$ in the age-matched healthy subject and in the patient with Parkinson's disease (PD). N1 (I), P2 (I) - the components of evoked potentials on the first conditional and N1 (II), P2 (II)—on the second test stimuli. In the PD patient, the N1-P2 complexes appearing on second stimuli have greater amplitudes, hence the postexcitatory inhibition is reduced compared to control subject. Vertical solid bars correspond to the onset of auditory signals. Numerals in \% represent value of paired-pulse inhibition calculated using the following formula: (A1 - A2)/A1*100 where A1 and A2 are amplitudes of the N1 (I)/ P2 (I) and N1 (II)/ P2 (II) components, respectively.

cortical inhibition was substantially reduced compared to control subjects for ISIs 500, 700, and $900 \mathrm{~ms}$. Figure 1 demonstrates the native EEG recordings of the healthy agematched control and of the patient with Parkinson's disease. The recordings clearly illustrate greater amplitudes of N1-P2 complexes following the second stimulus of a pair in the $\mathrm{PD}$ patient than in the control subject at ISIs of 700 and $900 \mathrm{~ms}$. The mean values of PPI in the group of PD patients were decreased to $29.8 \pm 4.8 \%(P<.01), 25.4 \pm 3.2 \%(P<.001)$, and $15.1 \pm 2.6 \%(P<.001)$ for intervals 500,700 , and $900 \mathrm{~ms}$, respectively, as compared to these values $(54.1 \pm 4.2 \% ; 49.8 \pm$ $2.3 \%$ and $42.9 \pm 2.7 \%$ ) in the group of age-matched controls. It was observed that the postexcitatory cortical inhibition became statistically significantly affected on the stages of PD corresponding to 1.5-2.0 of Hoehn and Yahr [26] scale. Where PD was advanced, the reduction of inhibition was expressed even stronger (Table 2). The mean amplitude of
N1-P2 complex elicited by a single (first) auditory stimulus in the group of PD patients was $16.2 \pm 0.8 \mathrm{mcV}$ which was less than in age-matched subjects $(18.5 \pm 1.6 \mathrm{mcV})$ but this difference was not statistically significant $(P>.05)$.

3.2. Correlation Study. Correlation analysis revealed negative connection $(P<.05)$ between the averaged value of the PPI (evaluated for ISIs of 500, 700 and $900 \mathrm{~ms}$ ) and age of both healthy subjects (Figure 2) and PD patients (Table 3 ). In the group of PD patients, the negative correlation $(P<$ .05 ) between the PPI value and the age at the onset of the disease was also observed. It was further revealed that the reduction of cortical inhibition negatively affected the cognitive functions: lower values of PPI corresponded to decreased MMSE scores and vice versa. The degree of PPI correlated positively with the summary MMSE score $(P<.01)$ and with the score of attention plus memory 
TABLE 2: Inhibition of the second N1-P2 complex of cortical auditory evoked potentials at paired-click stimulation in age-matched control group and patients with Parkinson's disease (Mean \pm SE).

\begin{tabular}{|c|c|c|c|c|}
\hline \multirow{3}{*}{ Study groups } & \multicolumn{3}{|c|}{ Inhibition in $\%$ of the second N1-P2 } & \multirow{3}{*}{ Averaged } \\
\hline & \multicolumn{3}{|c|}{ complex at interstimulus intervals } & \\
\hline & $500 \mathrm{~ms}$ & $700 \mathrm{~ms}$ & $900 \mathrm{~ms}$ & \\
\hline $\begin{array}{l}\text { Age-matched control; } \\
N=22\end{array}$ & $54.1 \pm 4.2$ & $49.8 \pm 2.3$ & $42.9 \pm 2.7$ & $48.0 \pm 2,1$ \\
\hline PD patients with stage & * & $* *$ & $* *$ & $* *$ \\
\hline $1.5-2.0 ; N=29$ & $31.1 \pm 6.6$ & $27.2 \pm 3.0$ & $18.0 \pm 3.3$ & $24.1 \pm 2,3$ \\
\hline PD patients with stage & $*$ & $* *$ & $* *$ & $* *$ \\
\hline $2.5-3.0 ; N=29$ & $28.0 \pm 5.7$ & $23.9 \pm 5.4$ & $12.6 \pm 4.0$ & $19.3 \pm 3,1$ \\
\hline \multirow{2}{*}{ All PD patients; $N=58$} & $*$ & $* *$ & $* *$ & $* *$ \\
\hline & $29.8 \pm 4.8$ & $25.4 \pm 3.2$ & $15.1 \pm 2.6$ & $21,4 \pm 2,4$ \\
\hline
\end{tabular}

The inhibition was defined: $(\mathrm{A} 1-\mathrm{A} 2) / \mathrm{A} 1 * 100$, where $\mathrm{A} 1$ is amplitude of the first and A2 is amplitude of the second evoked potential upon paired-click auditory stimulation. ${ }^{*} P<.01 ;{ }^{*} P<.001$ compared to control subjects (ANOVA, Mann-Whitney $\mathrm{U}$ test). $N$ :-number of subjects in the investigated groups.

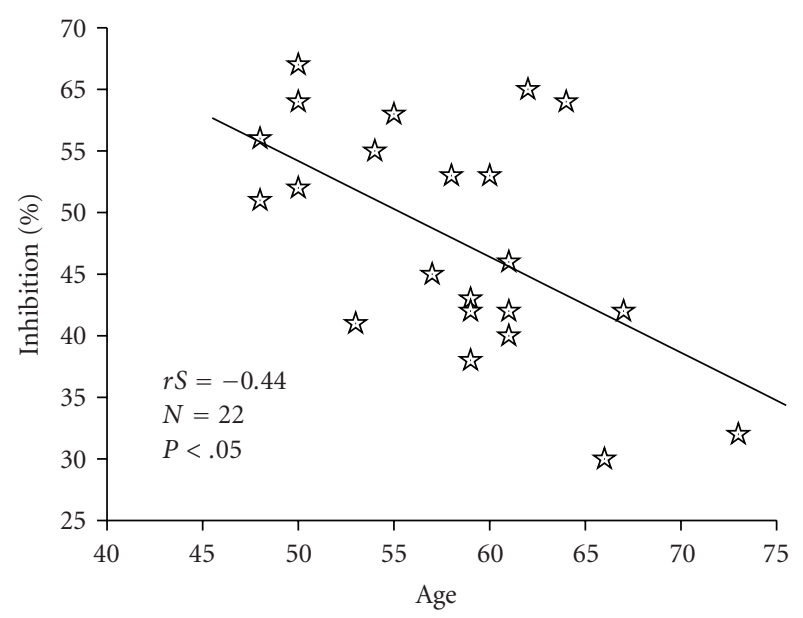

FIgURE 2: Correlation of the averaged value of the paired-pulse inhibition (evaluated for ISIs of 500, 700, and $900 \mathrm{~ms}$ ) and age of the healthy age-matched subjects. $r S$ is a coefficient of nonparametric Spearman rank-order correlation. N:-number of control subjects.

$(P<.001)$. No significant relationship was observed between the PPI value and the summary UPDRS score. Only negative association $(P<.01)$ of the body bradykinesia score (point 31 of UPDRS) with the PPI value was observed. The scores of the other UPDRS subitems had no significant correlation with the PPI value. Levodopa dosage and duration of the Levodopa intake did not significantly influence the brain capacity for inhibition. We did not observe any significant correlation between the PPI value and sex, disease duration, or Hoehn and Yahr stage (Table 3 ).

\section{Discussion}

The main result of this study showed that PD patients had significantly reduced PPI of the N1/P2 component of evoked potentials in the auditory cortex for ISIs 500, 700, and $900 \mathrm{~ms}$ compared to the healthy age-matched subjects. The degree of PPI correlated negatively with age of both control individuals
TABle 3: Correlation coefficients between the averaged value of the paired-pulse inhibition (PPI) and the characteristics of the PD patients.

\begin{tabular}{lc}
\hline Characteristics of the PD patients & $\begin{array}{c}\text { Averaged value of PPI } \\
(\%) \text { in patients } \\
(N=58)\end{array}$ \\
\hline Age & $-0.29^{*}$ \\
Sex & 0.13 \\
Disease duration & -0.04 \\
Age of the onset of the disease & $-0.28^{*}$ \\
Hoehn and Yahr stage & -0.15 \\
Summary UPDRS score & -0.14 \\
Body bradykinesia score & $-0.35^{* *}$ \\
(point 31 of UPDRS) & $0.10(N=46)$ \\
Duration of the levodopa intake & $0.28(N=46)$ \\
Levodopa dosage & $0.40^{* *}$ \\
Summary MMSE score & $0.43^{* * *}$ \\
Attention and memory score & (points 3 plus 4 of MMSE)
\end{tabular}

Averaged value of PPI was evaluated for 500, 700, and $900 \mathrm{~ms}$ interstimulus intervals. $N$ :-number of patients. Level of significance: ${ }^{*}$ is $P<.05$; $* *$ is $P<.01$; $* * *$ is $P<.001$ (nonparametric Spearman rank-order correlation).

and PD patients. In the group of PD patients, a positive correlation of the PPI value with the MMSE cognitive scores and a negative correlation with age of disease onset and body bradykinesia scores of the patients were observed.

Our results of decreased inhibition in the auditory cortex are consistent with the data on a reduced postexcitatory inhibition in the motor cortex in the patients with PD $[6,8-$ $10,12,32,33]$. Decreased cortical inhibition is also in agreement with the data on a reduced postexcitatory inhibition of the midlatency auditory (P49) and somatosensory (P13-N18, P24-N31, P44-N75) evoked responses to paired stimulation in $\mathrm{PD}$ patients $[22,23]$. These facts give us evidence that deficient inhibitory mechanisms may be specific not only for cortical but also for subcortical structures in PD. 
PPI is usually considered to reflect presynaptic changes in transmitters release [13-15]. Inhibitory GABA-dependent properties are great contributor to PPI. As already established [34], afferent volleys after initial excitatory postsynaptic potentials (EPSPs) result in inhibitory postsynaptic potentials (IPSPs). A system of GABAergic interneurons, which can be activated by direct and indirect stimulations, may play the major role in the genesis of these IPSPs [34, 35]. The synaptic release of GABA is suggested to be mediated by presynaptic GABA receptors of the B-type $[18,36,37]$. There is also strong evidence that DA may regulate inhibitory transmission at the synapses between pyramidal cells and interneurons by activating D1-like receptors located on the presynaptic terminals of GABAergic axons $[38,39]$. Calcium and sodium channels are potential DA targets $[40,41]$. It is noteworthy that DA reveals regulation of both spontaneous and evoked GABA release in cortical neurons $[39,42]$.

Another possible explanation of the reduced inhibition in the auditory cortex in patients with PD may be the loss of dopaminergic transmission in the basal ganglia and the dysfunction of the caudal pallidum that sends its direct projections to the inferior colliculus, medial geniculate nucleus, and temporal cerebral cortex [43]. The basal ganglia appear to "gate" sensory inputs at various levels [44] and activation of basal ganglia outputs (entopeduncular nucleus and substantia nigra pars reticulate) is able to inhibit sensory responses [45].

The decreased inhibition of the second cerebral evoked response on paired or repetitive auditory and somatosensory stimulations also was shown in some other neurological and psychiatric diseases: in patients with Huntington's disease [46], with myoclonus [47], in schizophrenic subjects [48], and in Down's syndrome individuals [49]. Several researches presented convincing data demonstrating association between the deficit in inhibitory capacity and cognitive impairment $[24,50]$. For example, in schizophrenics, decreased level of attention correlated with the increased ratio of the second to the first amplitude of the P50 auditory evoked response in a paired stimulus [50]. Recent studies that used a prepulse inhibition paradigm revealed a significant reduction of inhibitory processes in the auditory cortex in individuals suffering from PD dementia and dementia with Lewy bodies [24]. A prepulse inhibition paradigm is considered to reflect the state of attention control or ability to filter out repeated irrelevant sensory information $[51,52]$. In line with the above-mentioned studies, our data about significant positive correlation of the PPI value in auditory cortex with summary MMSE score $(r S=0.40, P<.01)$ and attention plus memory score of MMSE $(r S=0.43, P<.001)$ provide additional evidence that a deficit of inhibition might contribute to cognitive disturbances in PD patients.

In the present study, along with a correlation between the degree of PPI and cognitive indices, we found a negative association of the body bradykinesia scores of the PD patients with PPI value $(r S=-0.35, P<.01)$. This fact may be interpreted as evidence of the essential participation of the brain inhibitory processes in motor realizations that need sensory guidance, such as rapidity, amplitude of movements, and arm swings while walking (cheirokinesis).
Interestingly, a recent study which investigated possible associations between cognitive status and six different motor activities (facial expression, tremor, rigidity, bradykinesia, axial impairment, speech) found that only bradykinesia and speech significantly correlated with incident dementia in PD patients [53].

Our investigation showed that the degree of PPI in the auditory cortex correlated negatively with the age of both control individuals and PD patients. Age-related decrease in PPI was described earlier in motor cortex of healthy subjects during paired-pulse transcranial magnetic stimulation $[54,55]$. Inhibitory processing deficit related with age was observed also in study of the cortical auditory evoked potential N2 in two groups of young and elderly participants [56]. Based on experimental researches, it is possible to suppose that this age-dependent decline of inhibition is due to a decrease of the density of GABAergic neurons and alteration of the GABA-receptors composition in the neocortex in aged subjects $[57,58]$. Some researchers suggest that the age-related deficit of inhibitory function results in inability to suppress effectively the irrelevant information that causes cognitive impairment and deterioration in motor performance with advancing age $[59,60]$.

Our data showed negative connection $(r S=-0.28, P<$ .05 ) between the PPI value and the age of PD onset. Perhaps, an important determinant of inhibitory dysfunction in PD is the combined effect of the natural aging process (senescence of cerebrum) and neurodegenerative changes, characteristic for this disease. Notably, several studies reported the relationship between the age of the disease onset and cognition, namely, older age at disease onset was associated with more marked cognitive decline in PD patients [61-63].

Recently, there have been a lot of discussions regarding the influence of Levodopa-containing preparations on cerebral functions. While one study proved the absence of negative influence of Levodopa-therapy [63], another revealed that Levodopa can worsen cerebral activity [64]. In this study, we did not find any significant dependence of PPI value on duration of the Levodopa intake and Levodopa dosage.

Overall, this study demonstrated that: (i) the PPI in response to paired auditory stimulation was significantly reduced in patients with PD compared to control subjects; (ii) the value of PPI in the auditory cortex correlated negatively with the age of both control individuals and PD patients; (iii) the value of the brain inhibitory function correlated positively with cognitive functions and negatively with age of the disease onset and body bradykinesia scores of the PD patients. We propose two possible mechanisms for the reduced postexcitatory cortical inhibition in PD: dopaminergic transmission deficiency in the basal ganglia and functional impairment of GABAergic cortical interneurons caused by lack of dopamine regulating influences through the depletion of dopaminergic innervation in the cerebral cortex. Our findings may suggest that preparations, being the derivatives of GABA, can be useful in medication of PD. Phenibut (Noofen) belongs to such preparations and it is able to activate cerebral inhibitory GABAergic system $[65,66]$. Application of Noofen in complex therapy 
of PD appeared effective for the improvement of cognitive functions, enhancement of emotional state, and increase of social adaptation of the PD patients [67].

\section{References}

[1] G. E. Alexander and M. D. Crutcher, "Functional architecture of basal ganglia circuits: neural substrates of parallel processing," Trends in Neurosciences, vol. 13, no. 7, pp. 266-271, 1990.

[2] G. N. Lewis and W. D. Byblow, "Altered sensorimotor integration in Parkinson's disease," Brain, vol. 125, no. 9, pp. 2089-2099, 2002.

[3] A. Sailer, G. F. Molnar, G. Paradiso, C. A. Gunraj, A. E. Lang, and R. Chen, "Short and long latency afferent inhibition in Parkinson's disease," Brain, vol. 126, no. 8, pp. 1883-1894, 2003.

[4] K. R. Chaudhuri, P. Martinez-Martin, A. H. V. Schapira et al., "International multicenter pilot study of the first comprehensive self-completed nonmotor symptoms questionnaire for Parkinson's disease: the NMSQuest study," Movement Disorders, vol. 21, no. 7, pp. 916-923, 2006.

[5] M. R. DeLong, "Primate models of movement disorders of basal ganglia origin," Trends in Neurosciences, vol. 13, no. 7, pp. 281-285, 1990.

[6] M. C. Ridding, R. Inzelberg, and J. C. Rothwell, "Changes in excitability of motor cortical circuitry patients with Parkinson's disease," Annals of Neurology, vol. 37, no. 2, pp. 181-188, 1995.

[7] D. J. Surmeier and S. T. Kitai, "State-dependent regulation of neuronal excitability by dopamine," Nihon Shinkei Seishin Yakurigaku Zasshi, vol. 17, no. 2, pp. 105-110, 1997.

[8] M. Pierantozzi, M. G. Palmieri, M. G. Marciani, G. Bernardi, P. Giacomini, and P. Stanzione, "Effect of apomorphine on cortical inhibition in Parkinson's disease patients: a transcranial magnetic stimulation study," Experimental Brain Research, vol. 141, no. 1, pp. 52-62, 2001.

[9] R. Cantello, R. Tarletti, and C. Civardi, "Transcranial magnetic stimulation and Parkinson's disease," Brain Research Reviews, vol. 38, no. 3, pp. 309-327, 2002.

[10] M. Bareš, P. Kaňovský, H. Klajblová, and I. Rektor, "Intracortical inhibition and facilitation are impaired in patients with early Parkinson's disease: a paired TMS study," European Journal of Neurology, vol. 10, no. 4, pp. 385-389, 2003.

[11] F. Morgante, A. J. Espay, C. Gunraj, A. E. Lang, and R. Chen, "Motor cortex plasticity in Parkinson's disease and levodopainduced dyskinesias," Brain, vol. 129, no. 4, pp. 1059-1069, 2006.

[12] J. Chu, A. Wagle-Shukla, C. Gunraj, A. E. Lang, and R. Chen, "Impaired presynaptic inhibition in the motor cortex in Parkinson disease," Neurology, vol. 72, no. 9, pp. 842-849, 2009.

[13] J. K. Angleson and W. J. Betz, "Monitoring secretion in real time: capacitance, amperometry and fluorescence compared," Trends in Neurosciences, vol. 20, no. 7, pp. 281-287, 1997.

[14] C. Lévénès, H. Daniel, P. Soubrié, and F. Crépel, "Cannabinoids decrease excitatory synaptic transmission and impair long-term depression in rat cerebellar Purkinje cells," Journal of Physiology, vol. 510, no. 3, pp. 867-879, 1998.

[15] B. Szabo, I. Wallmichrath, P. Mathonia, and C. Pfreundtner, "Cannabinoids inhibit excitatory neurotransmission in the substantia nigra pars reticulata," Neuroscience, vol. 97, no. 1, pp. 89-97, 2000.
[16] E. Neher, "Vesicle pools and Ca2+ microdomains: new tools for understanding their roles in neurotransmitter release," Neuron, vol. 20, no. 3, pp. 389-399, 1998.

[17] K.-Z. Shen and S. W. Johnson, "Presynaptic GABA(B) and adenosine A1 receptors regulate synaptic transmission to rat substantia nigra reticulata neurones," Journal of Physiology, vol. 505, no. 1, pp. 153-163, 1997.

[18] Z. Chu and J. J. Hablitz, "GABAB receptor-mediated heterosynaptic depression of excitatory synaptic transmission in rat frontal neocortex," Brain Research, vol. 959, no. 1, pp. 39-49, 2003.

[19] S. Lei and C. J. McBain, "GABAB receptor modulation of excitatory and inhibitory synaptic transmission onto rat CA3 hippocampal interneurons," Journal of Physiology, vol. 546, no. 2, pp. 439-453, 2003.

[20] G. J. Stuart, "Determinants of spike timing-dependent synaptic plasticity," Neuron, vol. 32, no. 6, pp. 966-968, 2001.

[21] L. L. Voronin and E. Cherubini, "'Deaf, mute and whispering' silent synapses: their role in synaptic plasticity," Journal of Physiology, vol. 557, no. 1, pp. 3-12, 2004.

[22] K. Nakashima, T. Nitta, and K. Takahashi, "Recovery functions of somatosensory evoked potentials in parkinsonian patients," Journal of the Neurological Sciences, vol. 108, no. 1, pp. 24-31, 1992.

[23] C. Teo, L. Rasco, K. Al-Mefty, R. D. Skinner, F. A. Boop, and E. Garcia-Rill, "Decreased habituation of midlatency auditory evoked responses in Parkinson's disease," Movement Disorders, vol. 12, no. 5, pp. 655-664, 1997.

[24] M.-P. Perriol, K. Dujardin, P. Derambure et al., "Disturbance of sensory filtering in dementia with Lewy bodies: comparison with Parkinson's disease dementia and Alzheimer's disease," Journal of Neurology, Neurosurgery and Psychiatry, vol. 76, no. 1, pp. 106-108, 2005.

[25] E. P. Lukhanina, M. T. Kapustina, N. M. Berezetskaya, and I. N. Karaban, "Reduction of the postexcitatory cortical inhibition upon paired-click auditory stimulation in patients with Parkinson's disease," Clinical Neurophysiology, vol. 120, no. 10, pp. 1852-1858, 2009.

[26] M. M. Hoehn and M. D. Yahr, "Parkinsonism: onset, progression and mortality," Neurology, vol. 17, no. 5, pp. 427-442, 1967.

[27] A. J. Hughes, Y. Ben-Shlomo, S. E. Daniel, and A. J. Lees, "What features improve the accuracy of clinical diagnosis in Parkinson's disease: a clinicopathologic study," Neurology, vol. 42, no. 6, pp. 1142-1146, 1992.

[28] S. Fahn, R. Elton, and Members of the UPDRS Development Committee, "Unified Parkinson's disease rating scale," in Recent developments in Parkinson's disease, S. Fahn, C. D. Marsden, D. B. Calne, and M. Goldstein, Eds., vol. 2, pp. 153-163, 293-304, New Jersey Macmillan Health Care Information, Florham Park, NJ, USA, 1987.

[29] R. G. Holloway, I. Shoulson, S. Fahn et al., "Pramipexole vs levodopa as initial treatment for Parkinson Disease: a 4-year randomized controlled trial," Archives of Neurology, vol. 61, no. 7, pp. 1044-1053, 2004.

[30] H. Davis, T. Mast, N. Yoshie, and S. Zerlin, "The slow response of the human cortex to auditory stimuli: recovery process," Electroencephalography and Clinical Neurophysiology, vol. 21, no. 2, pp. 105-113, 1966.

[31] R. W. Angel, W. M. Quick, C. C. Boylls, M. Weinrich, and R. L. Rodnitzky, "Decrement of somatosensory evoked potentials during repetitive stimulation," Electroencephalography and Clinical Neurophysiology, vol. 60, no. 4, pp. 335-342, 1985. 
[32] A. Berardelli, S. Rona, M. Inghilleri, and M. Manfredi, "Cortical inhibition in Parkinson's disease: a study with paired magnetic stimulation,” Brain, vol. 119, no. 1, pp. 71-77, 1996.

[33] B. U. Kleine, P. Praamstra, D. F. Stegeman, and M. J. Zwarts, "Impaired motor cortical inhibition in Parkinson's disease: motor unit responses to transcranial magnetic stimulation," Experimental Brain Research, vol. 138, no. 4, pp. 477-483, 2001.

[34] K. Krnjević, M. Randić, and D. W. Straughan, "Nature of a cortical inhibitory process," Journal of Physiology, vol. 184, no. 1, pp. 49-77, 1966.

[35] R. Hanajima and Y. Ugawa, "Intracortical inhibition of the motor cortex in movement disorders," Brain and Development, vol. 22, no. 1, pp. S32-S135, 2000.

[36] H.-R. Olpe, M. W. Steinmann, K. Greiner, and M. F. Pozza, "Contribution of presynaptic GABA-B receptors to pairedpulse depression of GABA-responses in the hippocampus," Naunyn-Schmiedeberg's Archives of Pharmacology, vol. 349, no. 5, pp. 473-477, 1994.

[37] R. A. Deisz, "GABA(B) receptor-mediated effects in human and rat neocortical neurones in vitro," Neuropharmacology, vol. 38, no. 11, pp. 1755-1766, 1999.

[38] C. Bergson, L. Mrzljak, J. F. Smiley, M. Pappy, R. Levenson, and P. S. Goldman-Rakic, "Regional, cellular, and subcellular variations in the distribution of D1 and D5 dopamine receptors in primate brain," Journal of Neuroscience, vol. 15, no. 12, pp. 7821-7836, 1995.

[39] C. Gonzalez-Islas and J. J. Hablitz, "Dopamine inhibition of evoked IPSCs in rat prefrontal cortex," Journal of Neurophysiology, vol. 86, no. 6, pp. 2911-2918, 2001.

[40] D. J. Surmeier, J. Bargas, H. C. Hemmings Jr., A. C. Nairn, and P. Greengard, "Modulation of calcium currents by a D1 dopaminergic protein kinase/phosphatase cascade in rat neostriatal neurons," Neuron, vol. 14, no. 2, pp. 385-397, 1995.

[41] A. R. Cantrell, V. C. Tibbs, R. E. Westenbroek, T. Scheuer, and W. A. Catterall, "Dopaminergic modulation of voltagegated $\mathrm{Na}+$ current in rat hippocampal neurons requires anchoring of cAMP-dependent protein kinase," The Journal of Neuroscience, vol. 19, RC21, pp. 1-6, 1999.

[42] F.-M. Zhou and J. J. Hablitz, "Dopamine modulation of membrane and synaptic properties of interneurons in rat cerebral cortex," Journal of Neurophysiology, vol. 81, no. 3, pp. 967-976, 1999.

[43] S. J. Shammah-Lagnado, G. F. Alheid, and L. Heimer, "Efferent connections of the caudal part of the globus pallidus in the rat," Journal of Comparative Neurology, vol. 376, no. 3, pp. 489507, 1996.

[44] H. Boecker, A. Ceballos-Baumann, P. Bartenstein et al., “Sensory processing in Parkinson's and Huntington's disease. Investigations with 3D H215O-PET," Brain, vol. 122, no. 9, pp. 1651-1665, 1999.

[45] J. S. Schneider, "Interactions between the basal ganglia, the pontine parabrachial region, and the trigeminal system in cat," Neuroscience, vol. 19, no. 2, pp. 411-425, 1986.

[46] F. Kanda, K. Jinnai, K. Takahashi et al., "Somatosensory evoked potentials in Huntington's disease-studies with paired stimulation," Electromyography and Clinical Neurophysiology, vol. 29, no. 5, pp. 287-291, 1989.

[47] Y. Ugawa, K. Genba, T. Shimpo, and T. Mannen, "Somatosensory evoked potential recovery (SEP-R) in myoclonic patients," Electroencephalography and Clinical Neurophysiology, vol. 80, no. 1, pp. 21-25, 1991.
[48] H. T. Nagamoto, L. E. Adler, M. C. Waldo, J. Griffith, and R. Freedman, "Gating of auditory response in schizophrenics and normal controls. Effects of recording site and stimulation interval on the P50 wave," Schizophrenia Research, vol. 4, no. 1, pp. 31-40, 1991.

[49] E. W. P. Schafer and H. V. S. Peeke, "Down syndrome individuals fail to habituate cortical evoked potentials," American Journal of Mental Deficiency, vol. 87, no. 3, pp. 332-337, 1982.

[50] C. M. Cullum, J. G. Harris, M. C. Waldo et al., "Neurophysiological and neuropsychological evidence for attentional dysfunction in schizophrenia," Schizophrenia Research, vol. 10, no. 2, pp. 131-141, 1993.

[51] M .E. Dawson, A. M. Schell, N. R. Swerdlow, and D. L. Filion, "Cognitive, clinical and neurophysiological implications of startle modification," in Attention and Orienting: Sensory and Motivational Processes, P. J. Lang, R. F. Simons, and M. T. Balaban, Eds., pp. 257-279, Lawrence Erlbaum, Hillsdale, NJ, USA, 1997.

[52] A.. Elden and M. A. Flaten, "The relationship of automatic and controlled processing to prepulse inhibition," Journal of Psychophysiology, vol. 16, no. 1, pp. 46-55, 2002.

[53] G. Levy, M.-X. Tang, L. J. Cote et al., "Motor impairment in PD: relationship to incident dementia and age," Neurology, vol. 55, no. 4, pp. 539-544, 2000.

[54] A. Peinemann, C. Lehner, B. Conrad, and H. R. Siebner, "Agerelated decrease in paired-pulse intracortical inhibition in the human primary motor cortex," Neuroscience Letters, vol. 313, no. 1-2, pp. 33-36, 2001.

[55] A. Oliviero, P. Profice, P. A. Tonali et al., "Effects of aging on motor cortex excitability," Neuroscience Research, vol. 55, no. 1, pp. 74-77, 2006.

[56] S. Bertoli and R. Probst, "Lack of standard N2 in elderly participants indicates inhibitory processing deficit," Neuroreport, vol. 16, no. 17, pp. 1933-1937, 2005.

[57] T. Hua, C. Kao, Q. Sun, X. Li, and Y. Zhou, "Decreased proportion of GABA neurons accompanies age-related degradation of neuronal function in cat striate cortex," Brain Research Bulletin, vol. 75, no. 1, pp. 119-125, 2008.

[58] S. Schmidt, C. Redecker, C. Bruehl, and O. W. Witte, "Age-related decline of functional inhibition in rat cortex," Neurobiology of Aging, vol. 31, pp. 504-511, 2010.

[59] A. Gazzaley, W. Clapp, J. Kelley, K. McEvoy, R. T. Knight, and M. D'Esposito, "Age-related top-down suppression deficit in the early stages of cortical visual memory processing," Proceedings of the National Academy of Sciences of the United States of America, vol. 105, no. 35, pp. 13122-13126, 2008.

[60] H. Fujiyama, M. I. Garry, O. Levin, S. P. Swinnen, and J. J. Summers, "Age-related differences in inhibitory processes during interlimb coordination," Brain Research, vol. 1262, no. C, pp. 38-47, 2009.

[61] H. L. Katzen, B. E. Levin, and M. L. Llabre, "Age of disease onset influences cognition in Parkinson's disease," Journal of the International Neuropsychological Society, vol. 4, no. 3, pp. 285-290, 1998.

[62] J. J. Locascio, S. Corkin, and J. H. Growdon, "Relation between clinical characteristics of Parkinson's disease and cognitive decline," Journal of Clinical and Experimental Neuropsychology, vol. 25, no. 1, pp. 94-109, 2003.

[63] D. Muslimović, B. Post, J. D. Speelman, and B. Schmand, "Cognitive profile of patients with newly diagnosed Parkinson disease,” Neurology, vol. 65, no. 8, pp. 1239-1245, 2005. 
[64] J. A. Cooper, H. J. Sagar, S. M. Doherty, N. Jordan, P. Tidswell, and E. V. Sullivan, "Different effects of dopaminergic and anticholinergic therapies on cognitive and motor function in Parkinson's disease," Brain, vol. 115, part 6, pp. 1701-1725, 1992.

[65] F. H. Marshall, "Is the GABAB heterodimer a good drug target?" Journal of Molecular Neuroscience, vol. 26, no. 2-3, pp. 169-175, 2005.

[66] F. H. Marshall and S. M. Foord, "Heterodimerization of the GABAB receptor-implications for GPCR signaling and drug discovery," Advances in Pharmacology, vol. 57, no. C, pp. 6391, 2010.

[67] N. Karaban, E. P. Lukhanina, N. A. Melnik, and N. M. Berezetskaya, "Influence of course treatment with Noofen on motor activity, cognitive functions and emotional state in patients with Parkinson's disease," Ukrainskiy Vestnik Psihonevrologii, vol. 14, no. 46, pp. 26-30, 2006. 


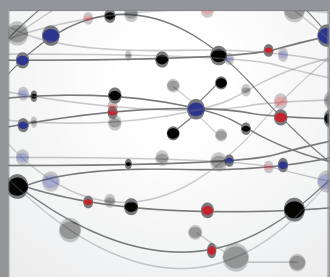

The Scientific World Journal
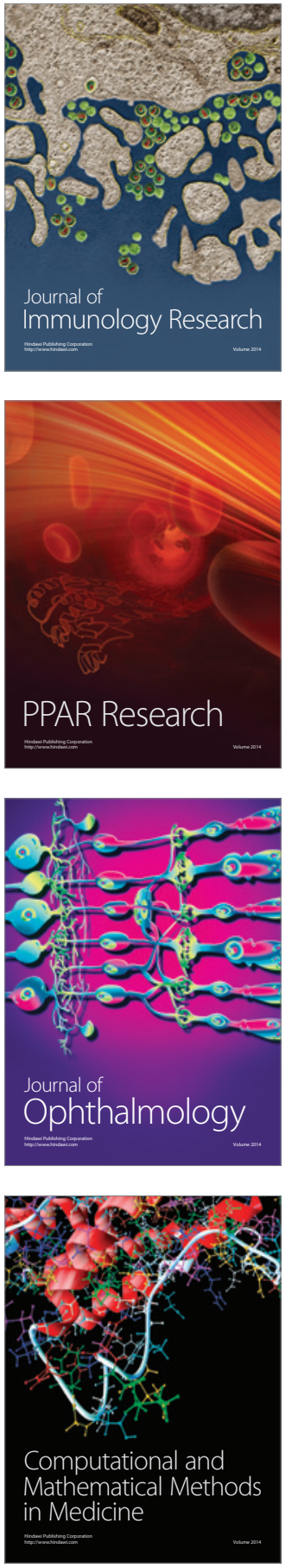

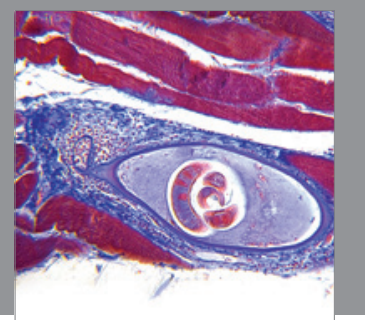

Gastroenterology

Research and Practice
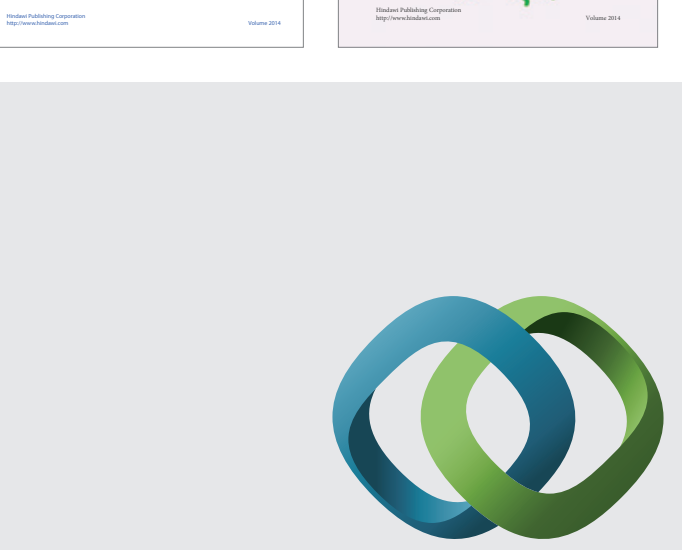

\section{Hindawi}

Submit your manuscripts at

http://www.hindawi.com
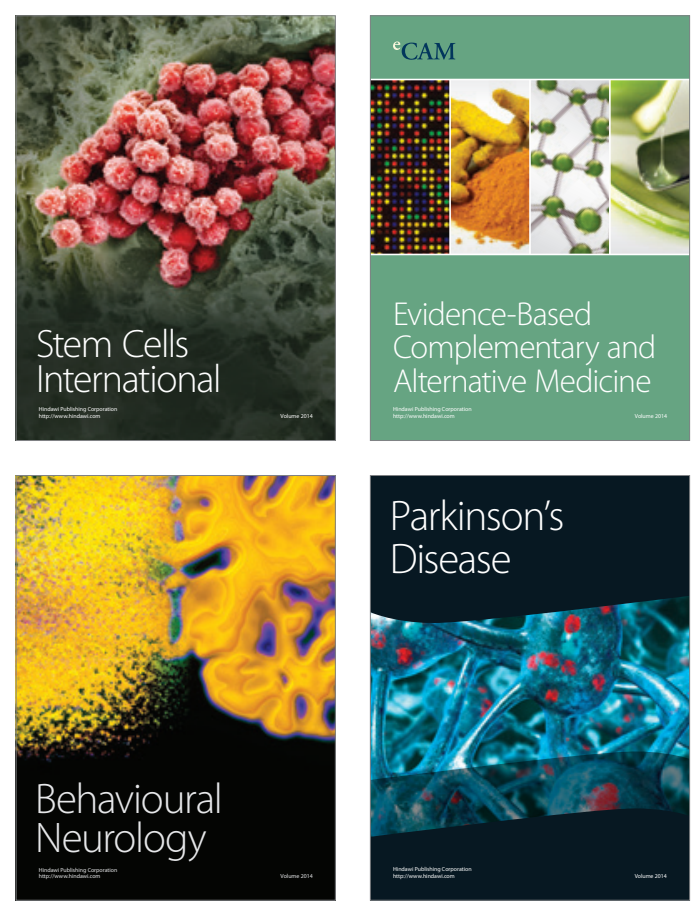

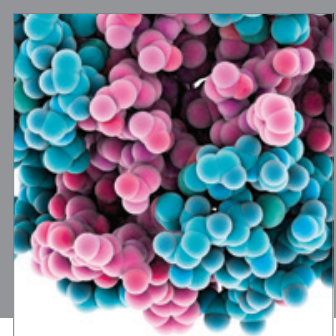

Journal of
Diabetes Research

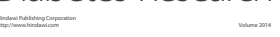

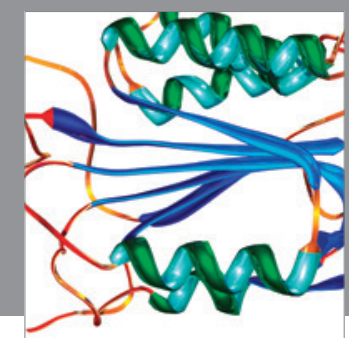

Disease Markers
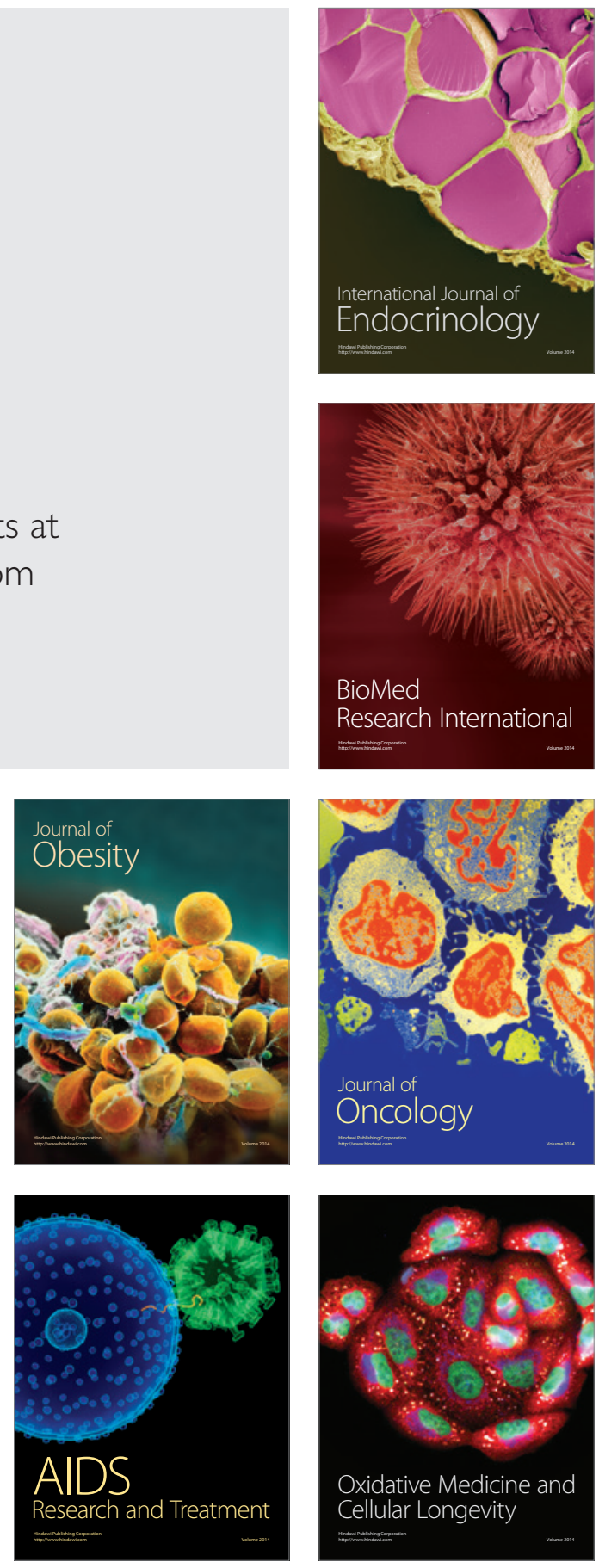